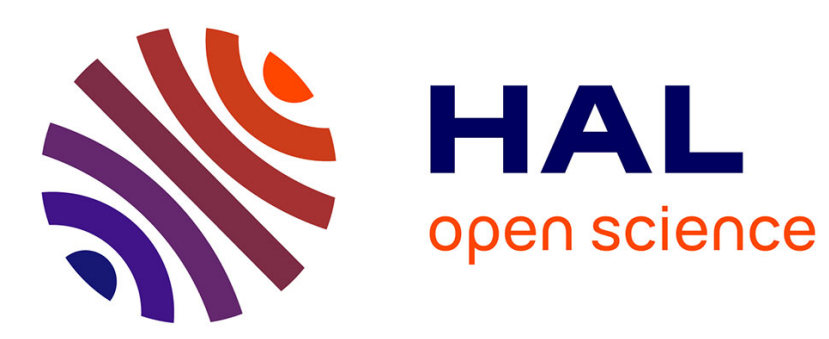

\title{
Soft Recovery Device For Shocked Brittle Materials
}

J. Ponsonnaille, P. Héreil

\section{To cite this version:}

J. Ponsonnaille, P. Héreil. Soft Recovery Device For Shocked Brittle Materials. Journal de Physique IV Proceedings, 1997, 07 (C3), pp.C3-289-C3-294. 10.1051/jp4:1997351 • jpa-00255508

\section{HAL Id: jpa-00255508 https://hal.science/jpa-00255508}

Submitted on 1 Jan 1997

HAL is a multi-disciplinary open access archive for the deposit and dissemination of scientific research documents, whether they are published or not. The documents may come from teaching and research institutions in France or abroad, or from public or private research centers.
L'archive ouverte pluridisciplinaire HAL, est destinée au dépôt et à la diffusion de documents scientifiques de niveau recherche, publiés ou non, émanant des établissements d'enseignement et de recherche français ou étrangers, des laboratoires publics ou privés. 


\title{
Soft Recovery Device For Shocked Brittle Materials
}

\author{
J.P. Ponsonnaille and P.L. Héreil* \\ DINALIS, rue Lavoisier, BP. 24, 91710 Vert le Petit, France \\ * Centre d'Études de Gramat, 46500 Gramat, France
}

\begin{abstract}
A device elaborated to soft recover brittle specimens loaded with a gas gun is presented. The target arrangement has been designed in order to minimize radial release waves in the specimen. $A$ new design of projectile is proposed to avoid parasite recompressions due to further impacts. The optimization of the whole system has been achieved by means of an iterative approach based on both 2D-calculations and experimentation. The efficiency of the system is demonstrated with the soft recovery of quartzite samples for projectile velocities up to $825 \mathrm{~m} / \mathrm{s}$.
\end{abstract}

Résumé : Un dispositif expérimental de récupération d'échantillon après choc est présenté. Le principe du dispositif est de placer l'échantillon dans un boitier métallique, dimensionné pour minimiser les ondes de détente latérales parasites. Le projectile a été conçu pour éviter les impacts supplémentaires. L'ensemble du système a été optimisé par une approche itérative meltant en oeuvre des simulations numériques et des expériences. L'efficacité du montage est montré à partir d'échantillons de quartzite récupérés après des vitesses d'impact allant de $140 \mathrm{~m} / \mathrm{s}$ à $825 \mathrm{~m} / \mathrm{s}$.

\section{INTRODUCTION}

The analysis of the soft recovered samples is of great importance to characterize a material under shock wave loading. Post-shock analysis offers a unique way to experimentally assess the behaviour of materials under a known uniaxial shock wave compression. This observation is therefore a guide for further theoretical modelling.

The efficiency of a recovery system is based on its ability to protect the sample from radial release waves which originate at the outer boundaries. In addition, this system has to ensure the soft deceleration of the target after the shock wave to avoid additional damage. In the past, a lot of designs have been proposed to recover metallic, ceramic or rock samples subjected to planar impact from explosives or gas gun experiments. Several reviews on shock-recovery techniques are presented in [1]-[5].

In the first approach of recovery system, termed 'momentum trapping', the sample is surrounded by a tightly fitting material of the same or nearly the same shock impedance. The surrounding materials prevent the sample from radial release waves and spallation. This recovery system has been used with some graduation, in the study of several metals and ceramics [6]-[11]. An alternative means to recover the central region of a target was proposed by Kumar and Clifton [12] as the 'star-shaped flyer'. This concept may be considered as an improvement of the simple spall ring used elsewhere. The idea is to select the target and flyer shapes which confine the lateral unloading waves to the outer regions of the target. The star-shaped flyer technique has been principally used on ceramics [13]-[20]. In the case of very brittle materials, the star-shaped flyer is of limited use particularly if the sample is high-fragmented by the shock wave effect. The only issue is therefore to adopt the first approach which confines the fragmented sample in a closed container and can ensure a correct recovery after impact. For instance, this system has been used to recover dense alumina [6], porous alumina [7], [9] and $\mathrm{B}_{4} \mathrm{C} / \mathrm{Al}_{2} \mathrm{O}_{3}$ [10] until an impact velocity of $1000 \mathrm{~m} / \mathrm{s}$.

The purpose of this paper is to present a soft recovery system to study a brittle material under planar shock wave generated with a gas gun. The geometry of the system has been optimized through a twodimensional finite element simulation and plate-impact experiments. We present the results collected on quartzite rock until an impact velocity of $825 \mathrm{~m} / \mathrm{s}$. 


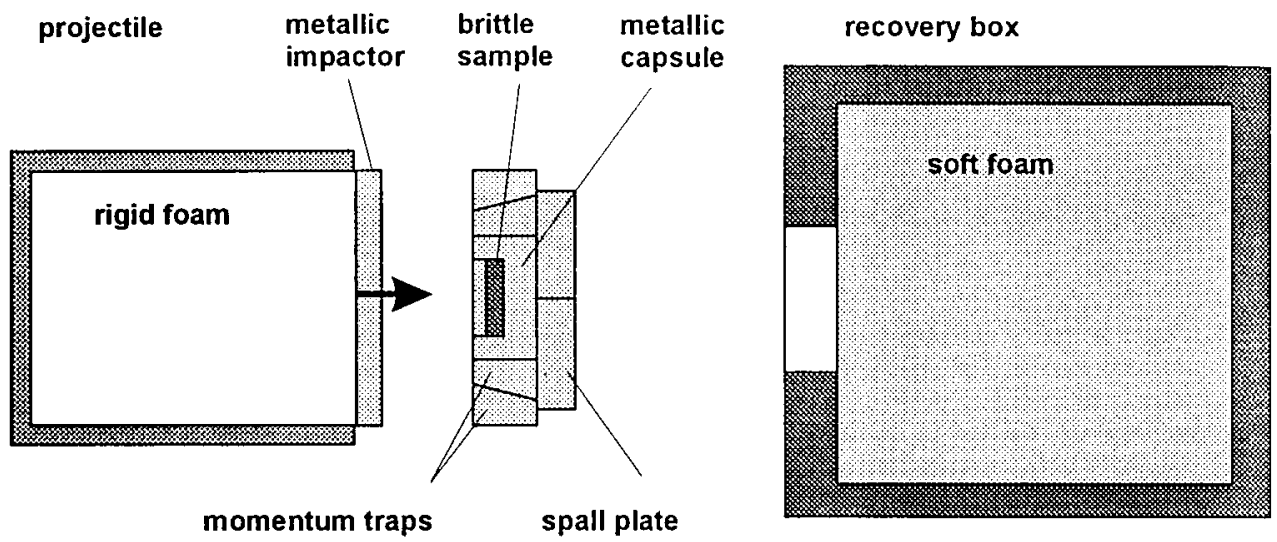

Figure 1 : Schematic of soft recovery technique

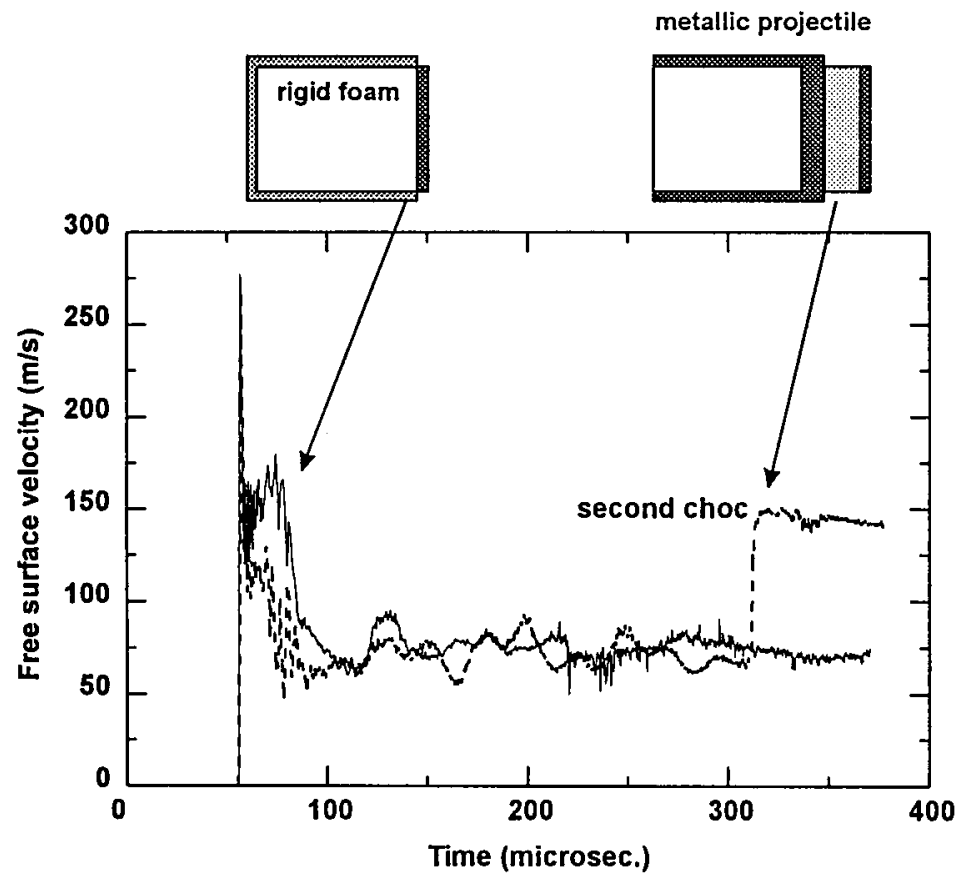

Figure 2 : Experimental configuration and free surface velocity profiles showing the second shock wave in the case of metallic projectile 


\section{EXPERIMENTAL CONFIGURATION}

A diagrammatic view of the recovery system is shown in figure 1 . With respect to standard plate-impact configuration, three elements have been modified. First, a new design of projectile is proposed to eliminate a secondary impact. Secondly, the assembly of the target has been optimized by numerical simulation to limit the effect of lateral release waves. Finally, the recovery box has been built to soft recover the sample by slowly decelerating the target.

\subsection{Projectile}

The projectile has been designed to protect the target from a secondary impact. In preliminary tests, we have used a projectile (see figure 2) composed of a metallic sabot which supports a 20-mm thick rigid foam and the 5-mm thick impactor plate. With this configuration, we observed some indications of second impact on the recovered capsule. Specific tests where then performed to elucidate this problem by recording the free surface velocity of the target with a VISAR system [21]. The experimental configuration of this test, shown in figure 2 , consists in an equivalent metallic target. The velocity profile shows a second shock $60 \mu \mathrm{s}$ after the first one. This shock corresponds to the impact of the metallic sabot on the target. It proves that the rigid foam is not sufficient to damp the kinetic energy of the sabot.

The new projectile design is composed of hollow balls of porous ceramic glued together and confined by a cylinder of nylon. The VISAR measurement performed with this new projectile presents no second shock on the velocity profile (figure 2). After the test, we observed that the ceramic balls were fully fragmented. During the test, the measured default of impact flatness was equal to $1 \mathrm{mrad}$. Therefore, the resistance of the projectile to the acceleration in the launcher is good.

\subsection{Recovery capsule}

The target assembly shown in figure 1 has been designed through numerical calculations using the finite element code LSDYNA2D. The specimen geometry consisted of a 5-mm thick, 30-mm diameter sample set in a metallic capsule closed by a 5-mm thick cover plate. The capsule is surrounded by two concentric momentum trapping rings tapered with a $27^{\circ}$ angle. The external diameter of the whole system is $100 \mathrm{~mm}$. The capsule is protected from spallation by a $20-\mathrm{mm}$ spall plate which is cut in four quadrants to avoid further impacts in the recovery box. The machining of the surface was carefully conducted to increase the fitting between all the elements of the target, especially between the sample and the capsule.

\subsection{Recovery box}

The recovery box consists of a steel container filled with low density polyurethane foam. A hole whose diameter is a little larger than that of the capsule is located on the front face. Stopping the recovery capsule is achieved on a length of 3 meters for the maximum impact velocity of $825 \mathrm{~m} / \mathrm{s}$. The distance between the target and the recovery box is long enough to avoid the entry of the four quadrants of the spall plate into the box. During the test, the trajectories of these quadrants are not aligned with the barrel axis, therefore they are stopped on the front face of the recovery box. This device prevents further impacts between the recovered capsule and the spall plate during capsule deceleration. 


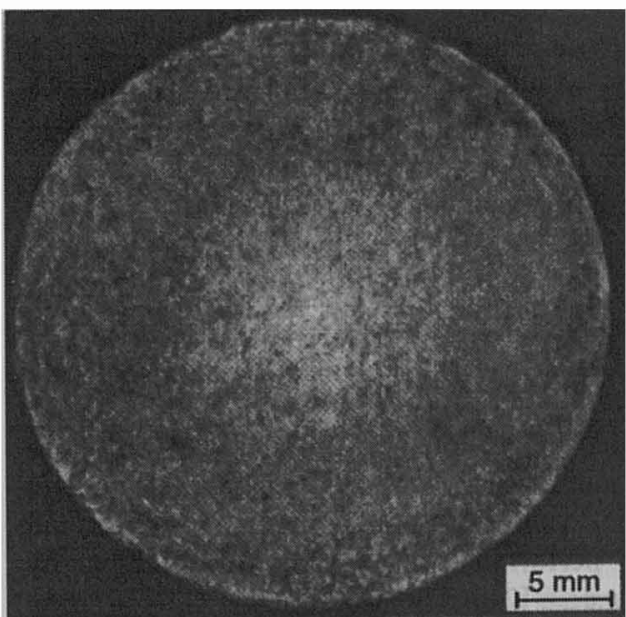

Figure 3 : Photography of quartzite sample recovered after test \#2
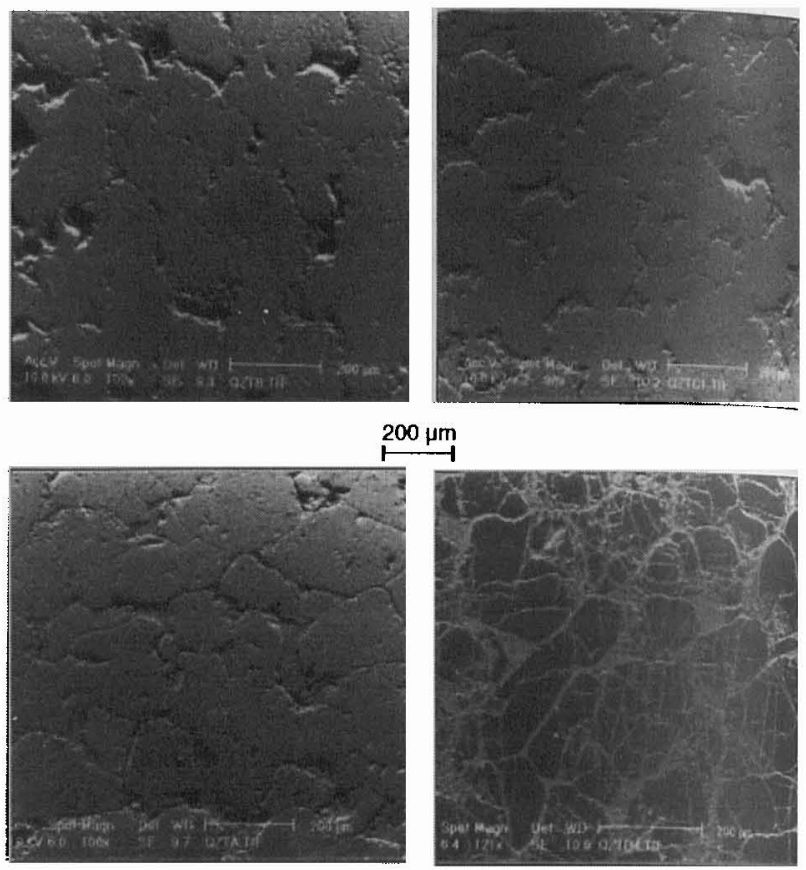

Figure 4 : Micrographies of quartzite samples

a) virgin material b) test \#1, $\mathrm{vp}=158 \mathrm{~m} / \mathrm{s}$

c) test \#2, Vp=340 m/s d) test \#3, Vp=825 m/s

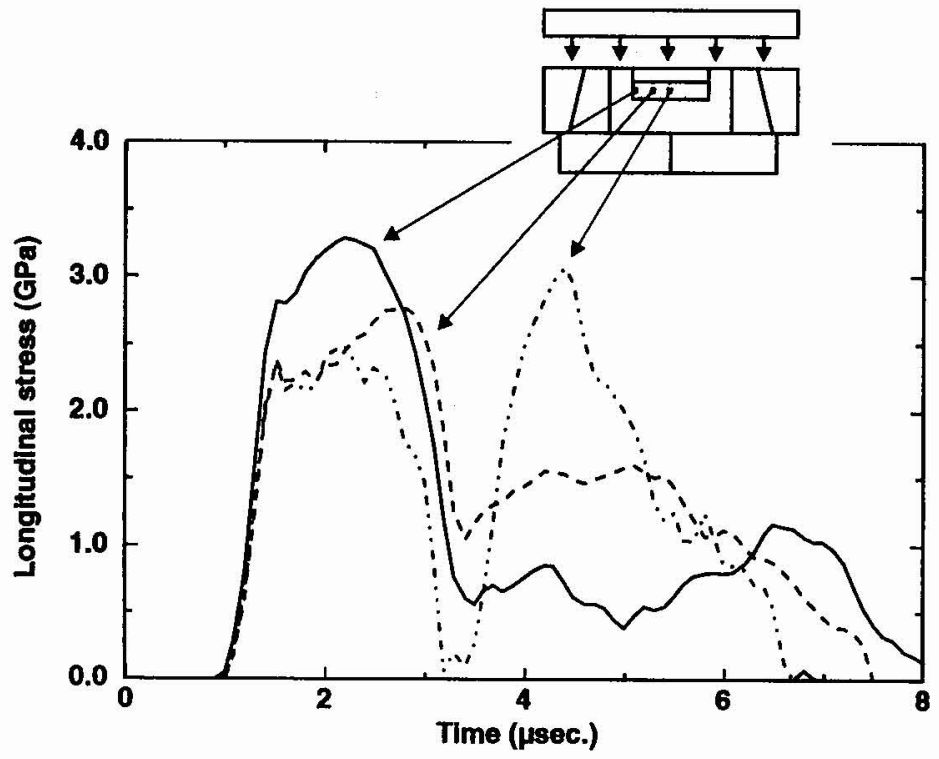

Figure 5 : Stress wave profile calculated at three locations inside the quartzite sample. 


\section{EXPERIMENTAL RESULTS ON QUARTZITE}

The system presented above has been used to soft recover quartzite samples up to an impact velocity of $825 \mathrm{~m} / \mathrm{s}$. Quartzite is a polycrystalline rock composed of fine quartz grains ( $20 \mu \mathrm{m}$ of average size). The density of the samples ranges from $2.4 \mathrm{~g} / \mathrm{cm}^{3}$ to $2.5 \mathrm{~g} / \mathrm{cm}^{3}$ which corresponds to a porosity between $6 \%$ and $10 \%$. Three recovery experiments have been conducted to study the shock behaviour of this rock. In the two first ones, the impactor and the metallic parts of the target were in 2024 aluminium alloy. The quartzite samples and the metallic cover plates are $5-\mathrm{mm}$ thick. The impact velocities are $158 \mathrm{~m} / \mathrm{s}$ and 340 $\mathrm{m} / \mathrm{s}$ respectively for test\#1 and test $\# 2$.

In the third experiment (test\#3), the impact velocity is $825 \mathrm{~m} / \mathrm{s}$ and a TA6V alloy (Ti-6Al-4V) has been used instead of $\mathrm{Al} 2024$. It has been found that the aluminium use is limited to an impact velocity of about $600 \mathrm{~m} / \mathrm{s}$, above which the deformations of the capsule are too significant. In the third experiment, the metallic cover plate is $5-\mathrm{mm}$ thick. The quartzite sample is composed of two disks. The first one, the nearest to the cover plate, is $5-\mathrm{mm}$ thick and the second one is $25-\mathrm{mm}$ thick. This modified configuration was able to delay the release waves from the back of the target assembly.

All the three target assemblies (sample, metallic capsule and cover plate) were recovered intact after shock experiments. A photography of the sample recovered in test\#2 (figure 3) shows the good result obtained with this system. The recovered samples are coated and sectioned along a diameter before polishing for micrography examination. The micrographies presented in figure 4 show the evolution of the cracking micromechanism for this rock as a function of shock conditions. The virgin material is reported as reference. The characteristics of quartzite show that the maximum stresses achieved in the tests are respectively equal to $1.1 \mathrm{GPa}, 2.4 \mathrm{GPa}$ and $6.5 \mathrm{GPa}$ for impact velocities of $158 \mathrm{~m} / \mathrm{s}, 340 \mathrm{~m} / \mathrm{s}$ and $825 \mathrm{~m} / \mathrm{s}$. The Hugoniot Elastic Limit of quartzite is about $2.2 \mathrm{GPa}$, then test\#1 is below the HEL, test\#2 just above and test\#3 corresponds to a three times higher value. Figure 4 shows that the micrographies of sample \#1 are very similar to those of the virgin material. The grain are in contact and no trace of cracking can be distinguished. Sample \#2 shows that decohesion between grains occurs predominately at HEL, with a few cracks inside them. In sample \#3, all the grains are cracked, so intragranular microcraking is the dominant mechanism of damage.

\section{TWO-DIMENSIONAL NUMERICAL SIMULATION}

The simulations are performed with the finite element code LSDYNA2D. Computer simulations are not only used to improve the design of the target assembly but also to evaluate the stress state in the quartzite sample. The dynamic behaviour of quartzite was represented by a pseudo TENSOR concrete/geological model. In order to perform more accurate simulation, some parameters were adjusted by comparison with velocity profiles obtained with a VISAR interferometer in previous plate-impact experiments.

Stress versus time profiles at three different points located at $R, R / 2$ and 0 (where $R$ is the radius of the sample) and at half thickness, are given in figure 5 for test $\# 2$. After the first initial compressive wave and the release wave coming from the back free surface of the impactor plate, a second compressive wave is present on the diagram. The intensity of this second loading is maximum at the centre of the sample. It is produced by the superposition of a compressive wave generated at the outer boundary. This wave results from the impedance mismatch between the sample and the metallic capsule. This situation was pointed out by several authors [4] [5]. The major difficulty of the metallic capsule technique lies in the fact that the metallic container properties are not completely compatible with those of brittle solids.

These results showing that the stress state in the sample is heterogeneous in space, reveal that the soft recovery techniques cannot be disconnected from other material studies, such as real-time wave-profile experiments and numerical calculations. The recovery of materials under shock wave condition is only one element in the interdisciplinary research devoted to the characterization of the dynamic behaviour of materials. 


\section{CONCLUSION}

This paper deals with the study of a soft recovery system for brittle material loaded with a gas gun. Three components have been designed in order to improve the recovery. A new design of projectile is proposed to avoid parasite recompressions due to secondary impact. The target assembly has been designed in order to minimize radial release waves in the sample. A recovery box filled with low density foam stops the target on a length of 3 meters for a maximum impact velocity of $825 \mathrm{~m} / \mathrm{s}$.

Improvement of the whole system has been achieved by an iterative approach based on both $2 \mathrm{D}$. calculations and experimentation. The efficiency of the system is demonstrated with the sof recovery of quartzite samples for projectile velocities of $158 \mathrm{~m} / \mathrm{s}, 340 \mathrm{~m} / \mathrm{s}$ and $825 \mathrm{~m} / \mathrm{s}$. For lower impact velocities, the metallic part of the target is A12024 and for the upper ones TA6V. Microstructural analysis of recovered samples indicates that just above the Hugoniot Elastic Limit, the failure mechanism of quartzite consists in grains decohesion. A shock loading stress equal to three times the HEL leads to an extensive microcracking of the grains.

Nevertheless, numerical calculations show that the stress state in the sample is heterogeneous. It implies that soft recovery techniques cannot be disconnected from other materials studies, such as real-time wave-profile experiments and numerical calculations. Recovering materials under shock wave condition is only one element in the interdisciplinary research devoted to the characterization of the dynamic behaviour of materials.

Acknowledgement. The authors would like to gratefully acknowledge the contributions of Yannick Sarrant for shock experiments.

\section{References}

[1] Metallurgical Effects at High Strain Rates (edited by R.W. Rohde, B.M. Butcher, J.R. Holland and C.H. Karners), Plenum, New York (1973)

[2] Shock Waves and High Strain Rate Phenomena in Metals (edited by M.A. Meyers and L.E. Murr), Plenum, New York (1981)

[3] Materials at High Strain Rates (edited by T.Z. Blazintsky), Elsevier/Applied Science, London (1987)

[4] Gray III G.T., in Shock Compression of Condensed Matter (1989) p. 407.

[5] Gray III G.T., in High-Pressure Shock Compression of Solids (1992) p. 187.

[6] Louro L.H, Lindford A. and Meyers M.A., Journal de physique, Colloque C3, Supplément $n^{\circ}$, Tome 49, (1988) p. 333.

[7] Louro L.H and Meyers M.A., in Shock Compression in Condensed Matter (1989) p. 465.

[8] Lassila D.H. and Gray III G.T., Journal de physique IV, Colloque C8 (1994) p. 349.

[9] Yeshurun Y., Brandon D.G., Venkert A. and Rosenberg Z., Journal de physique, Colloque C3, Supplément au $\mathrm{n}^{\circ} 9$, Tome 49, (1988) p. 11.

[10] Blumenthal W.R., Gray III G.T., in Shock Compression of Condensed Matter (1989) p. 393.

[11] Winkler W.D. and Nahme H., in High-Pressure Science and Technology (1993) p. 1663.

[12] Kumar P. and Clifton R.J., J. Appl. Phys., 48, n'11 (1977) p. 4850.

[13] Rabie R.L., Vorthman J.E. and Dienes J.K., in Shock Waves in Condensed Matter (1983) p. 199.

[14] Cagnoux J. and Longy F., Journal de Physique, Colloque C3, Suppl. au n ${ }^{\circ}$, tome 49 (1988) p.3.

[15] Longy F. and Cagnoux J., in Shock Compression of Condensed Matter (1989) p. 441.

[16] Chang S.N., Chung D.T., Ravichandran G. and Nemat-Nasser S., in Shock Compression of Condensed Matter (1989) p. 389.

[17] Kirkpatrick S.W., Curran D.R., Erlich D.C. and Klopp R.W., in Shock Compression of Condensed Matter (1991) p. 935.

[18] Espinosa H.D., Raiser G., Clifton R.J. and Ortiz M., J. Appl. Phys., 72, n8 (1992) p. 3451.

[19] Raiser G. and Clifton R.J., Journal of Engineering Materials and Technology, 15 (1993) p. 293

[20] Raiser G.F., Wise J.L., Clifton R.J., Grady D.E. and Cox D.E., J. Appl. Phys., 75, nº (1994)p. 3862.

[21] Barker L.M and Hollenbach R.E., J. Appl. Phys, 41 (1970) p. 4208 